\title{
Where is the humour in tourism promotion? An investigation of the "Spain Marks" campaign
}

\author{
Miriam Porres-Guerrero \\ University of Seville, Spain \\ mporresg@hotmail.com
}

\section{Concepción Foronda-Robles}

University of Seville, Spain

foronda@us.es

\begin{abstract}
This paper discusses humour and tourism, with a focus on "Spain Marks", an international campaign used to promote Spain as a tourism destination. The importance of this relationship suggests that the use of humour in marketing works as an engagement and loyalty strategy, as well as to portray the uniqueness of a destination. The "Spain Marks" campaign was innovative in its use of humour because it offered a fresh and contemporary image of Spain as a tourism destination. This campaign has been specially selected for its exceptional ironic character. The study aims to understand the humour appreciation of this specific advertisement using an online survey that was completed by 40 participants. The results indicate that the use of humour is a difficult task because what is perceived as fun, attractive and ironic in any tourism campaign is highly subjective.
\end{abstract}

Keywords: tourism, humour, experience, promotion, Spain Marks, irony.

\section{Introduction}

Humour, as a multidisciplinary construct, has attracted the attention of academics working in a variety of disciplines including education, sociology, psychology, medicine, anthropology, communication, linguistics and tourism (Brône et al. 2015; Critchley 2013; Falconer 2017; Fernández 2017; Fry 2011; Kuipers 2015; Lynch 2002; Mahony et al. 2002; Martin \& Ford 2018; Morreall 2014; Pearce \& Pabel 2015; Sliter et al. 2014).

The literature recognises humour as a subjective phenomenon, which depends on the cultural background of individuals, their mood and past experiences (Peterson \& Seligman 2004; Refaie 2011; Vuorela 2005). For some researchers, humour is a communicative form 
that results in positive emotional states (Francesconi 2017; Frew 2006; Ruch 2002), it is part of everyday life (Ulloth 2002), and it produces well-being in human beings (Collett 2004). To better understand the role of humour in enhancing peoples' subjective well-being, the literature also delves into the study of the sense of humour and the ability to laugh at oneself (Neuendorf \& Skalski 2001; Refaie 2011).

A current trend in tourism is for tourists to have authentic experiences while on holiday. Increasingly, this leads to tourism companies using humour during interactions with tourists so that their experiences are perceived as more engaging and memorable (Pabel \& Pearce 2016; Pabel 2017). As some researchers affirm, an emotional experience is vital for contemporary tourists (Io 2013; Poria et al. 2006; Reisinger \& Steiner 2006; Yeoman et al. 2007) in search of an authentic, genuine and active experience (Smith et al. 2010). Tourism is a vehicle to explore the emotions of people, and with it, positive emotions generated through humour. Positive emotions can become a promising strategy of loyalty and of the desire to stay longer in a tourist destination (Mitas et al. 2012).

Humour in the tourism sector plays an essential role in guaranteeing a pleasant experience for tourists, tourism employees, and local host communities (Cohen 2010; Frew 2006; Pabel \& Pearce 2015; 2018; Reisinger \& Turner 2012). Humour offers the opportunity to add value to the customer experience (Pabel \& Pearce 2018). However, care should be taken when using humour, as it may offend others for cultural or social reasons (Ball \& Johnson 2001; Barsoux 1993) or for generating misunderstandings based on linguistic differences (Spielmann \& Delvert 2014).

Tourist companies can use humour as part of their experiences or for promotional purposes. Guided tours, tourist campaigns, postcards, travel journals, photographs, and video blogs may all include various forms of humour (Pabel \& Pearce 2016). However only few studies have examined the relationship between humour and advertising in promoting tourism destinations (Bock 2014; Parente \& Strausbaugh-Hutchinson 2014; Haiko 2015). This study aims to investigate the humour applied to the promotional tourism campaign of "Spain Marks". This topic is considered to be novel and could provide fertile ground for future research.

\section{Literature review}

Advertisers understand that feelings and emotions are transmitted through humour, and this has the advantage of generating hedonic value (Ruch 1998) and empathy (Hampes 2010). However, it is also associated with certain risks (Dore 2018). Previous studies have investigated the impact of humour on advertising (Eisend 2009; Weinberger et al. 2015). Most professionals believe that humour works best in adverts targeted at younger customers (Madden \& Weinberger 1984). The literature also informs us that it is more complicated to achieve effective humour appreciation in print ads than in digital ones due to their limited sensory spectrum, making the use of humour in print ads a challenging undertaking (Chang \& Chang 2014, Skalski et al. 2009). Previous studies refer to different humour categories used in advertising (Crawford \& Gregory 2015), although in tourist campaigns, the most appealing humour technique types are considered to be satire, irony, puns and wittiness.

Well-applied humour is a resource that allows to engage the audience and feel connected to a brand. However, humour in advertising remains a minor strategic element because it can have harmful effects on the credibility of certain brands (Eisend 2009; Riecken \& Hensel 2012; 
Weinberger \& Gulas 1992). The underlying issue is that humour is a rather subjective phenomenon that requires appropriate decoding by the receiver (Attardo 2001). For these reasons it is often regarded as a double-edged sword, which can backfire if used incorrectly (Strick et al. 2012). Yet, humour is increasingly being used in emotional advertising (Geuens et al. 2011; Panda et al. 2013) helping to generate smiling brands (Valiente 2016) and leading to positive emotions (Carbelo \& Jauregui 2006).

Linking positive emotions to a brand generates more interest in a brand and may also arouse emotions in certain viewers to the point that they are surprised or laugh or even cry. There are three techniques used and applied in Spain to inject a dose of humour:

- Music branding, which is a form of communication framed as part of the experiential marketing strategy, to connect with the audience, create engagement and brand loyalty (Kemp et al. 2012; Morris \& Boone 1998). It was used in the "We love people" campaign in Seville from 2012 to 2013 (https://www.youtube.com/watch?v=d-xZ1P1IXOg).

- Sensory marketing, which tries to create experiences through the senses (Agapito et al. 2013; Hultén 2011), invites us to smell, see, taste, feel, listen and ultimately, to engage. The campaign "Travel to the La Rioja" (https://www.youtube.com/watch? $\mathrm{v}=\mathrm{iOEoS14t0G4)}$ in 2014 surprised the public by moving a little piece of La Rioja to the Madrid metro, which allowed metro users to enjoy the smells of this wine region.

- Another example is street marketing, which uses a visual communication approach and tries to get people to participate in this type of message, creating an emotional bond (Saucet \& Cova 2015). The campaign "The best climate in the world" took the Canary Islands to the streets of London (http://www.thebestclimateintheworld.com/discover?item=3). In November 2017, it addressed the British public by surprising them with hidden messages on trains, buses and taxis. The campaign played on the bad weather in Great Britain and invited its citizens to visit the islands. The messages could only be seen when the windows of selected trains, buses and taxis became foggy.

\subsection{Spanish tourist advertising}

Any country willing to market and sell its products and services to an international audience needs to establish a successful brand. However, choosing the right campaign to build a successful brand can be a risky and challenging task. Spain is an excellent example of a country that has been the victim of stereotypes (Andreu et al. 2000; Martínez \& Nicolás 2013; Mestre et al. 2008), of a sometimes poor strategic vision and of a lack of knowledge about visitors' needs (Nobs 2006) and how the country is indeed perceived as a destination.

Turespaña is Spain's destination marketing organisation (DMO) responsible for promoting Spain abroad as a tourism destination. Its main role is managing the tourism brand image of the destination to international markets. Turespaña has used eight major international advertising campaigns since its inception. These show a progressive strategy, making use of images and iconic elements to attract the attention of potential customers. The image of Spain has traditionally been based on three factors: 1) its pleasant climate and its beaches; 2) Spanish traditions and, 3) the character of the Spaniards (cheerful, spontaneous, hospitable and 
passionate) and their excellent hospitality and gastronomy. This image is projected through art, film and advertising, despite efforts to change it. In reality, this topical image is difficult to change and the same stereotypes prevail (Afinoguénova \& Martí-Olivella 2008; Storm 2013).

Historically, Spanish tourism promotions included the legendary "Spain is different" campaign in the mid-1960s, where advertising was focused on cultural tourism and high purchasing power. At the end of the 1970s, the content of the campaign focused on images based on sun, beaches and festivals. In 1984, the campaign "Everything under the sun" was launched, which aimed at a more diversified promotion of Spain. This campaign helped to build the brand values of Spain as a tourist destination. The next campaign was "Passion for life" in 1991, emphasising active lifestyle, and representing Spain as a destination for experiences. This slogan meant a great leap in the establishment of Spain's global image and its development as a brand. Other campaigns that followed include "Spain by" and "Bravo Spain" (Morgan \& Pritchard 2001). Spain seemed to have reached its promotional peak, since it was ranked as one of the world's top tourist destination offering some of the best tourism experiences (Fuentes-Luque 2016). In promotional terms, the word "Bravo" seemed to confirm this fact. Then in 2002, "Spain Marks" was launched as a groundbreaking campaign that based its creative axis on considering the country as a tourist destination with its own personality, and by encouraging a way of understanding life that will leave its mark on visitors. This campaign also included a dose of humour, which is the main reason why it was chosen as a basis for analysis in this study. Then in 2014, "Smile! You are in Spain" emerged as a campaign that captured unexpected moments of foreign tourists during their visit to Spain. The current "I need Spain" campaign aims to consolidate Spain's position as a tourist destination in the European market, and raises awareness of this destination to emerging markets such as Asia (Corbacho et al. 2014; Garín-Muñoz \& de Juan 2012; Llorens Bahena 2013; Mariottini 2012; Mirna \& Igor 2016; Plumed 2012).

\subsection{The "Spain Marks" campaign}

According to market analyses carried out by Turespaña, it was necessary to find a slogan that added new emotional and inclusive characters to promote Spain (Fuentes-Luque 2016). This campaign aimed to reflect the emotions of visitors, leaving behind the traditional images associated with Spain such as sun and beach. "Spain Marks" (2002) promotes an image of a more contemporary lifestyle, and also plays with irony and humour in the purest Spanish style. Using only a few words in the adverts, the campaign showcases a new, fresh and contemporary image of Spain (Rocamora 2004).

The campaign was distributed in 17 countries, and the text was translated into ten languages (English, French, German, Italian, Portuguese, Russian, Japanese, Finnish, Swedish and Danish). Zentropy Partners, a global internet professional services company, was responsible for the online campaign. Besides spreading through the primary promotional channels, the campaign was also on display at the monographic exhibition of Spain STEPS (Spanish Tourism Exchange for Professionals) hosted through special presentation by the Spanish Office of Tourism in London. Originally, the campaign was expected to last at least four years. However, it was not well-received and therefore its actual lifecycle was shorter.

The "Spain Marks" campaign had a great social impact because it was novel and diverged from previous marketing campaigns, whilst remaining loyal to the underlying concepts of the original image of Spain (e.g. Spanish culture, gastronomy and art). There are few references to 
the short duration of the campaign, although some authors suggest that this Spanish advertising campaign did not present synergistic messages abroad, which generated conflicting messages in the promotion (Noya 2003).

The headline of the campaign shares the same conceptual structure regardless of the language in which the text appears, "España Marca" in Spanish, "Spanien prägt Sie" in German, "Spain Marks" in English or "Touchée par l'Espagne" in French.

The campaign is aimed at target audiences from different international backgrounds, both in terms of age group and travel motivations, so that everyone feels they can connect with the campaign. The campaign involves the viewer in a way that captures their attention and engages them with the tourism experiences on offer in Spain. The adverts could have also used images of Spaniards, but since the goal was to attract international tourists, they portray foreign characters.

The campaign consists of 20 black and white portraits, made by the Catalan fashion photographer, José Manuel Ferrater. The characters in the adverts represent international tourists showcasing a range of experiences that are related to the Spanish culture: art, language, history, traditions, gastronomy and nature. The images highlight how their visit to the country has affected them, leaving emotional and sometimes physical marks as a footprint of their holiday in Spain.

A discourse is constructed in which history and heritage become a commercial product. The base of the campaign is the rich cultural offer of Spain, which aims to reduce seasonality and focuses on tourism experiences such as gastronomic tourism; the pilgrimage of the Camino de Santiago; museums to discover artists; and language tourism among others. The principal creative resources were quite simple: to make potential tourists believe that if they come to Spain, they will be touched by the Spanish way of life and feel different. The focus on emotions is what differentiates Spain as a destination from its competitor countries (Bernabéu \& Rocamora 2010).

To understand the message, it is necessary to join different pieces that appear in the advertisement and to fit them as if it were a mental puzzle. The message is communicated when the viewer observes the image in black and white, contrasts it and relates it to the smaller, coloured image and finally understands the meaning of the slogan. Without needing the text, most of the messages could be deciphered and interpreted as positive, but with some of them, the text is necessary to understand the message.

In the case of Figure 1, the text helps to understand the aim of this advertisement. It exposes the unique characteristic of the Spanish language in its lip piercing. Language tourism is an important part of Spain's cultural tourism, attracting a growing number of visitors who travel to this destination to study Spanish. 


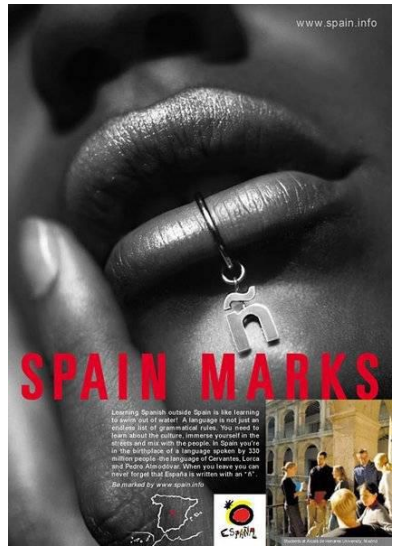

Figure 1. Language Tourism. Source: Turespaña

Figures 2 and 3 represent examples of gastronomic tourism. The face is a reflection of the soul, and these two advertisements are clear examples of this. Facial expressions and gestures are very powerful ways of transmitting meaning and emotions, such as joy. Figure 2 portrays a woman with a toothpick in her mouth, symbol of the tapa, and in her eyes, one can see the amusing drunkenness of Spanish wine. The face has the ability to capture that moment which invites us to share and to enjoy new flavours. On the other hand, an unfortunate bite may become a memory of the good times (Figure 3). The image also implies the important virtue of being able to laugh at oneself irrespective of the inconveniences of a particular situation. Everything is worthwhile if the experience was enjoyed through the five senses (Figure 3).
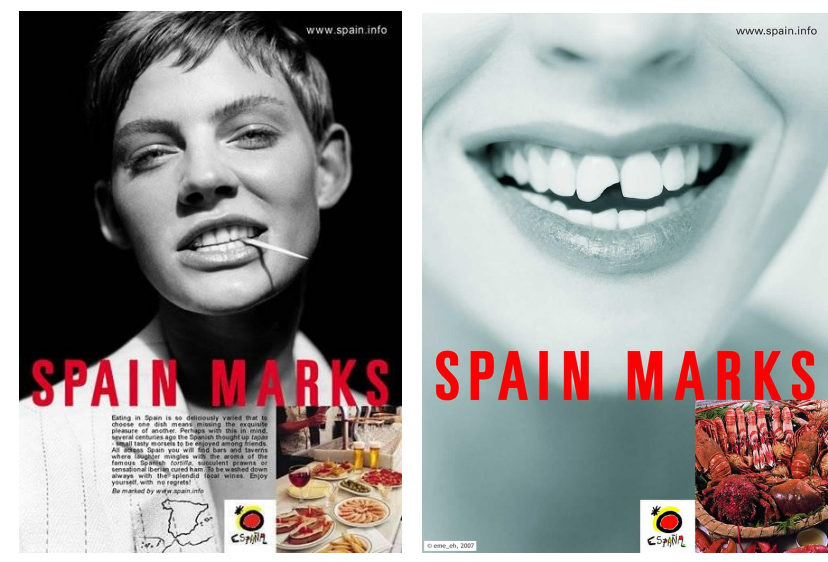

Figures 2 and 3. Gastronomic tourism. Source: Turespaña

In the promotion of the Spain brand, the traditional sun and beach tourism could not be absent, referring to the Canary Islands, the Balearics and the Mediterranean coast (Figures 4, 5 and 6). This time the humour is expressed through the skin marks after having been exposed to the sun for too long, i.e. wearing a bikini, diving mask or flip-flops. The images show that excess exposure to sun may cause sunburns, ageing skin and eye diseases. Unfortunately, long hours of sunshine are part of everyday life in Spain, which can be seen by returning tourists with red and sunburnt skin. 

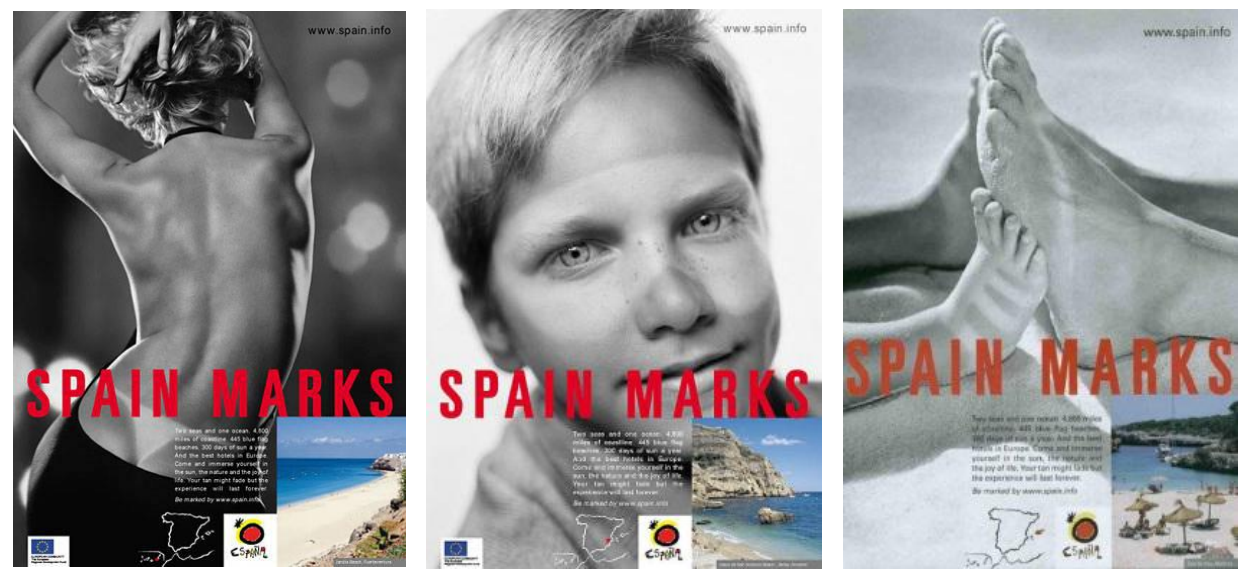

Figures 4, 5 and 6. Seaside tourism. Source: Turespaña

\section{Materials and method}

\subsection{Research aim}

The review of the previous literature shows that the use of humour in advertising campaigns of a destination helps to produce positive emotions and to generate future intentions to visit certain places. This paper aims to understand the appreciation of humour on a specific advertising campaign, in this case, "Spain Marks". This campaign has been selected because it is especially interesting for its exceptionally ironic character and its uniqueness in the application of humour in advertising Spain as a tourism destination.

\subsection{Research material and design}

An online survey was conducted to find out if the public recognized the application of humour in the advertisements and if they perceived the campaign as humorous. The online questionnaire was open in the month of May 2018 and was completed by 40 participants through Google Forms. Half of the respondents were Spanish, and the other half consisted of foreign nationalities, i.e. Germany, Hungary, Italy, United Kingdom, China, Colombia and Mexico. The majority of respondents were women (63\%), with an average age of 30.

The survey was designed so that the respondents could first view several advertisements from the "Spain Marks" campaign and then answer the questions. The analysis focused on two aspects: first, the respondents' awareness of the campaign, and second, the respondents' perceptions of the campaign's humorous content.

The theoretical background of this method within tourism campaigns is based on psychology and culture (Goldstein 2013; Martin \& Ford 2018). This is because humorous campaigns add value to our understanding of humour appreciation from diverse cultural perspectives (Hatzithomas et al. 2011; Marra \& Holmes 2007), especially in regard to the relevance of humour (Yus 2016).

\subsection{Data analysis}

Closed-ended survey responses were analyzed using descriptive statistics. In an open-ended question, respondents were asked whether they could interpret the polysemic meaning of the

Open-access journal | www.europeanjournalofhumour.org 
images, i.e. the relationship between the large, black and white image and the smaller coloured one in the advertisements. These open-ended responses were thematically analyzed for the correctness of the response and summary statistics were used to quantitatively summarize and describe the collected data.

\section{Results}

\subsection{Perception of humour in the campaign}

The "Spain Marks" campaign was ingenious and innovative; however, the campaign lacked awareness and went largely unnoticed. This appears to be true even after 15 years when this survey was conducted.

\subsubsection{Meaning of the campaign}

The survey results indicate that the slogan "Spain Marks" was perceived negatively by 40 percent of respondents, and more than 60 percent of them were foreigners. Some of the messages in the campaign were lost in translations with the provided translations not effectively communicating the positive effect of the intended message (Comitre \& Valverde 2014; Marottini 2012; Bernabeu \& Rocamora 2010). Thus, the intended message was not understood correctly or misinterpreted or did not transfer the desired function of the campaign.

Some researchers have even suggested the more suitable slogan of "Spain's Indelible Mark" (Fuentes-Luque 2016). The "Spain Marks" slogan seems to be a literal translation from the Spanish "España deja huella" ("Spain makes a mark"), which was intended to refer to the wealth of experiences to be had in Spain and which will transform you. In any case, "Spain Marks" is not a good translation since it does not express a positive effect, so it fails to convey the appealing function of advertising, and even produced a reaction of rejection by some respondents. Thus, the negative effect of the translation was more pronounced in the participants of English-speaking countries, who in their entirety answered with a negative perception of the slogan.

Another fact to highlight is that the campaign was identical throughout the world, and we must consider that cultural factors influence humour appreciation and that it should therefore be presented using different strategies and techniques. This happens with the "I need Spain" campaign, which was adapted to the Asian market.

\subsubsection{Types of humour in the campaign}

The humour found in the images is mainly based on irony, double meanings and creative graphics. There is a famous Spanish quote stating: "tell me something with humour, and it will stay engraved, I will learn with it, I will be captivated and trapped", and that is, precisely, what "Spain Marks" was aiming to achieve. The campaign showcases images of potential tourists, who seemed to be moved physically and emotionally after visiting Spain. This impact is expressed visually through physical, intellectual or emotional marks (Cómitre \& Valverde 2014).

According to its creators, the promotional campaign was designed to be ironic, creative and diverse. Half of the respondents $(n=20)$ perceived the irony in the messages, while the 
other 50 percent was divided between irony and sarcasm/mockery. This finding may offer an explanation as to why the campaign caused an adverse effect on some people. It appears that some participants had difficulty in distinguishing irony from sarcasm, which are humorous typologies that are easy to confuse. The difference lies in the intention of its use, with sarcasm being considered to convey contempt and cause offense. However, this is quite the opposite to the real intention of the "Spain Marks" messages.

Irony and humour are helpful technique types to communicate certain vibes or moods. The ironic message varies in the degree of subtlety, concealment, obviousness and intellectual complexity, depending on the context. Participants were asked to rate the level of irony in the message of the images on a Likert scale ( $1=$ Strongly disagree, 2=Disagree, $3=$ Neutral, 4=Agree, $5=$ Strongly agree). The results are shown in Figure 7.

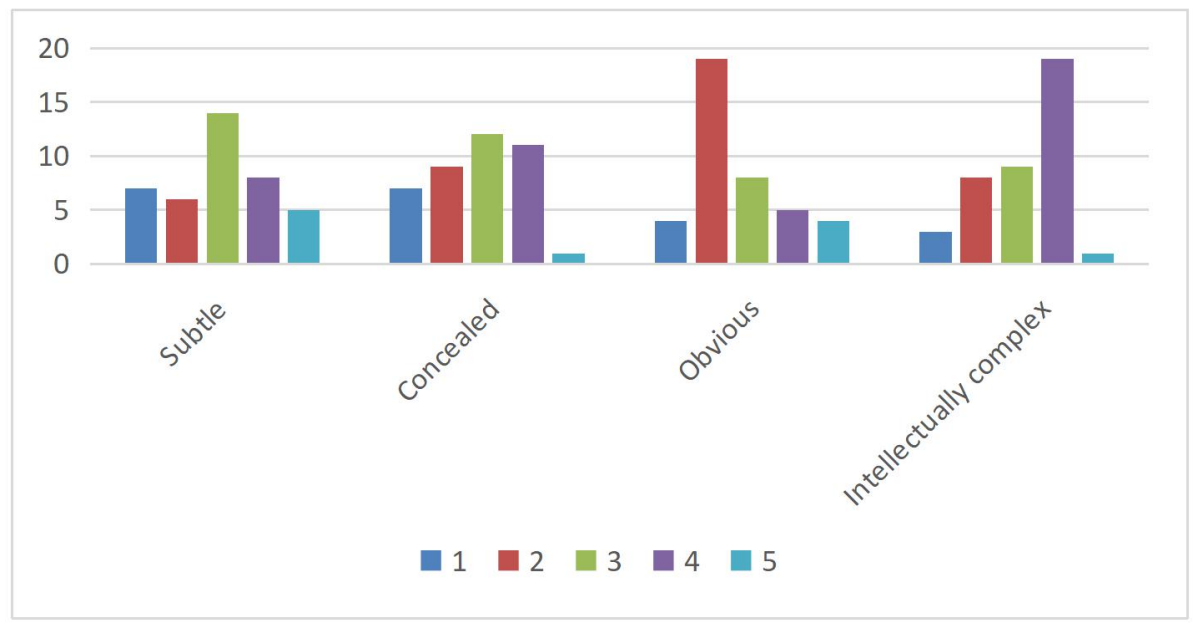

Figure 7. Perceived level of irony.

From the results, it is clear that the ironic messages were perceived by respondents as balanced subtly, not very obvious and of high intellectual complexity, since the message had to be deciphered by contrasting the images, reading the text and clarifying it with the rest of the message and its overall slogan. It is noteworthy that many of the texts that accompany the ads have a comic touch, which helps to decipher the humorous intent of the messages:

"It has been said that genius is catching. And Spain proves it. Goya, Dali, Picasso and Miró."

"Mix with the people and share their passion for life, until you almost forget where you're from."

"Learning Spanish outside Spain is like learning to swim out of water!"

"Come and immerse yourself in the sun, the nature and the joy of life. Your tan might fade but the experience will last forever."

It is also necessary to acknowledge that some figures were withdrawn from the campaign. For example, Figure 4 shows the tanned and bare back of a woman with the mark of a thong on her lower back. This image was perceived as "sexist" and demeaning to women by some 
viewers and was therefore excluded from the campaign. Although there is also the bare back of a man shown in another picture (Figure 13), this did not generate any conflict. Undoubtedly, these images of the male and female models can be interpreted as an assignment of gender roles by some viewers.

Irony is included in the campaign as an example of overcoming pain. The advert in Figure 8 invites tourists to be part of the miracle of the Camino de Santiago, to acquaint themselves with the nature, spirituality and hospitality of this walk. Pilgrims come from all over the world and subject their bodies to physical hardship by enduring this path of kindness and humility. The physical hardship is showcased in Figure 8 through bandaged and bruised feet. Another form of pain is portrayed in Figure 9, which shows the marks on a woman's legs after wearing the Roman caligae sandals, which were used by legionaries, and are known for leaving marks.

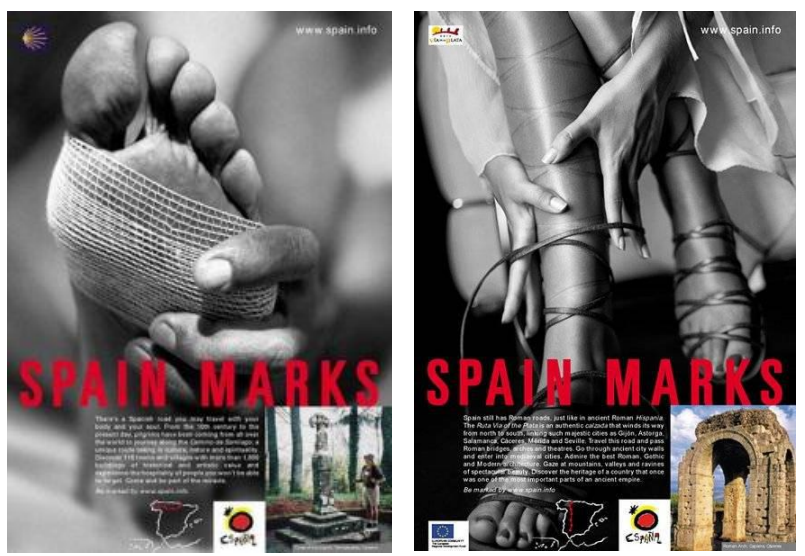

Figures 8 and 9. Cultural tourism. Source: Turespaña

In other cases, humour is applied by comparing the past with the present, through artwork (pictorial) that becomes comic. In this case, we refer to the woman's hairstyle in Figure 10 and man's moustache in Figure 11. Several of the respondents perceived these images as amusing, indicating that they recognized the artistic work presented in the smaller coloured image and therefore correctly interpreted the message in the ads. Figure 10 includes a smaller image of Las Meninas by Velázquez at the Museo del Prado in Madrid, which is an art piece that is known to provoke emotion and move people because it creates an uncertain connection between the viewer and the characters depicted in the painting. In this case, the humour is created by looking at the woman's curly hair (see Figure 10) which is styled in a similar way to the skirts of Las Meninas, in the form of an inverted basket. Alternatively, Dalí's moustache (Figure 11) offers a different symbol of identity, originality and fun. Salvador Dalí was a famous Spanish artist/draftsman known for his surrealist work. Both ads take us on a journey to Spain by using a combination of Spanish art and history. 

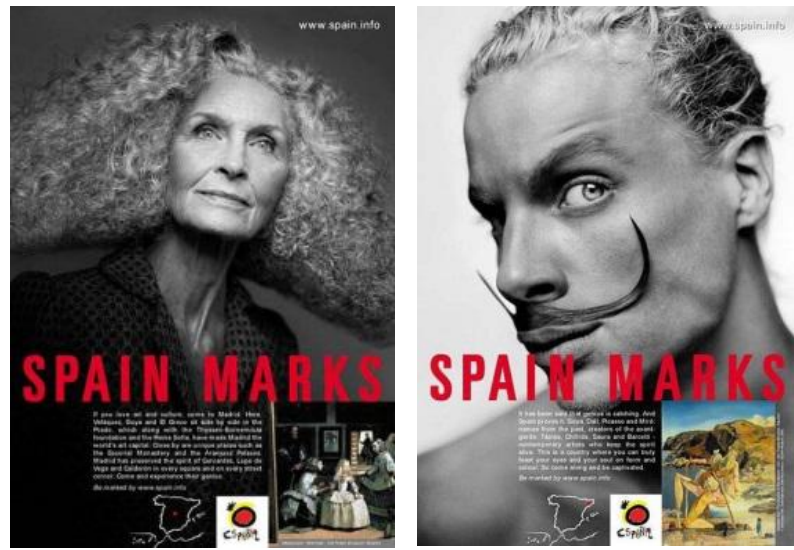

Figures 10 and 11. Artistic tourism. Source: Turespaña

Irony was created in the adverts through the use of double meanings. The images of the campaign are diverse to generate curiosity by reflecting on interesting contrasts, for example the popular and the cultured, the folkloric and the academic, the beach and the heritage. To make this type of humour work, language elements are used to create new meanings that are interpreted as comical by the consumer.

The semiotic singularity used in the graphic images are a powerful way of communicating meaning, and they also represent an interesting source of humour. Three campaign ads were presented to the research respondents who were asked to expose the polysemic meanings found in each of them (Figures 12, 13 and 14). These three ads were carefully selected since their double meaning was not portrayed in an obvious way.

The polysemic meaning of Figure 12 resides in that the belly button simulates a golf hole; Figure 13 makes a comparison between the man's backbone and a fishbone; and Figure 14 indicates the similarity between the man's hairstyle and the peaks of a mountain. Although most of the participants have provided the correct answers, 40 percent of them did not understand the polysemic relationships portrayed in the images. This reinforces the premise that some of the messages in the campaign were not understood by its target audience. In this case, misunderstandings were not only caused by the text and its translation but also by the images themselves.
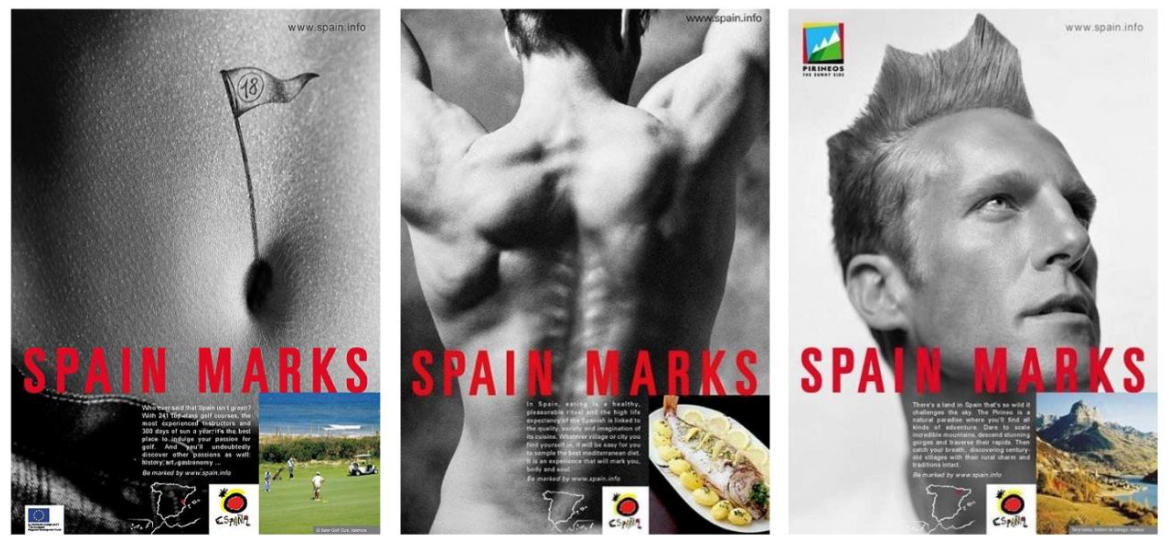

Figures 12, 13 and 14. Images with double meanings. Source: Turespaña 


\section{Conclusions}

This study aimed to obtain a better understanding about the perceptions of the advertising campaign "Spain Marks" based on an online survey with 40 respondents who were asked to rate the campaign for its use of humour.

Research on the application of humour in the tourism context is increasing (Frew 2006; Pearce \& Pabel 2015; Pabel \& Pearce 2016). In marketing and advertising, the use of humour has been found to generate interest and hedonic value in certain brands and to create positive emotions such as empathy and joy (Ruch 1998; Hampes 2010; Carbelo \& Jauregui 2006). Humour also works as a highly recommended engagement strategy. Most of the humour used during tourism experiences is predetermined or scripted in nature to ensure that its use is successful (Pabel \& Pearce 2018). This is because in the same way that there are benefits from its use, there are also disadvantages since there is always the possibility that the tourism audience does not understand or misinterpret the humour. Although laughter is universal, some jokes require complex reasoning and cognitive abilities to solve their incongruity. We believe that tourism organisations and agencies that are effectively using humour show exemplary merit and need to be internationally recognized.

After analyzing "Spain Marks" and its peculiarities, we can affirm that the application of humour is a difficult task because what is perceived as fun, attractive and ironic is highly subjective (Franzini 2012; Lewis 2006). Cultural, religious, and especially linguistic aspects create differences in the appreciation of humour. As seen in this study, irony could be difficult to understand when it was written in the text; therefore, the message of the campaign was also more difficult to decipher by the target audience.

Despite the weaknesses that were found in the campaign, we believe its value lies in the capacity for innovation by breaking away from the traditional norms of advertising. By analyzing the images, puns and irony generated by the campaign, it becomes clear that the humour in the adverts did not go unnoticed and was in fact quite striking and innovative. "Spain Marks", although no longer an active campaign, could still be in use showing the rich tourism experiences in Spain, and could also be considered a timeless campaign due to its contemporary image. Through the use of humour, the campaign generated a connection between the target audience and the tourist destination, creating interest and travel motivation for future tourists and recommendations by tourists who had visited the destination in the past. In this way, the campaign creates a spirit of loyalty and differentiation compared to other destinations that do not use humour in promoting their destination brand. The relationship between tourism and humour is clearly fascinating, as long as it is presented in a respectful and sensitive way.

Provocative and reflexive communication strategies seek to achieve greater social visibility, however care should be taken with such strategies because they may only be understood by a minority. In some campaigns, the images may bewilder the public, since they present real situations where the fictional world of advertising is eliminated. In recent years, advertisers have been looking for new ways to communicate and surprise consumers to remember the message. Some advertising campaigns prefer to improve the aesthetic quality of the advertising message and others choose to provoke.

Limitations of this study are its small sample size and the fact that the analysis was based on merely one tourism campaign. Therefore, care should be taken when generalizing the results of this study outside Spain or to other promotional campaigns. Future studies are

Open-access journal | www.europeanjournalofhumour.org 
needed which include larger and if possible longitudinal samples of respondents. Further analysis should also focus on other tourism promotional campaigns which use humour to allow for comparisons in the applied humour technique type and the respondents' humour perceptions.

Lastly, humour humanises us and fosters a stronger attitude towards life. It allows us to view things differently and increases our effectiveness to face novel situations. Humour is essential to get excited and socialize, which are important characteristics of the Spanish way of life.

\section{References}

Afinoguénova, E. \& Martí-Olivella, J. (2008). Spain Is (Still) Different: Tourism and Discourse in Spanish Identity. Lanham: Lexington Books.

Agapito, D., Mendes, J. \& Valle, P. (2013). 'Exploring the conceptualization of the sensory dimension of tourist experiences'. Journal of Destination Marketing \& Management 2 (2), pp. 62-73.

Andreu, L., Bigné, J. E. \& Cooper, C. (2000). 'Projected and perceived image of Spain as a tourist destination for British travellers'. Journal of Travel \& Tourism Marketing 9 (4), pp. 47-67.

Attardo, S. (2001). Humorous Texts: A Semantic and Pragmatic Analysis. Berlin and New York: Mouton de Gruyter.

Ball, S. \& Johnson, K. (2001). 'Humour in commercial hospitality settings', in Lashley, C. \& A. Morrison (eds.), In Search of Hospitality, London: Routledge, pp. 198-216.

Barsoux, J. L. (1993). Funny Business: Humour, Management and Business Culture. London: Cassell.

Bernabéu, A. \& Rocamora, R. (2010). 'De Spain is different a I need Spain. La función apelativa en campañas turísticas españolas'. Gran Tour 2, pp. 83-100.

Bock, S. (2014). 'What happens here, stays here: Selling the untellable in a tourism Advertising Campaign'. Western Folklore 73 (2-3), pp. 216-234.

Brône, G., Feyaerts, K. \& Veale, T. (eds.). (2015). Cognitive Linguistics and Humor Research. Berlin and New York: Mouton de Gruyter.

Carbelo, B. \& Jáuregui, E. (2006). 'Emociones positivas: humor positivo'. Papeles del psicólogo 27 (1), pp. 18-30.

Chang, W. Y. \& Chang, I. Y. (2014). 'The influences of humorous advertising on brand popularity and advertising effects in the tourism industry'. Sustainability 6 (12), pp. 9205 9217.

Cohen, E. (2010). 'Confirmation versus contestation of tourism theories in tourist jokes'. Tourism Analysis 15, pp. 3-16.

Collett, P. (2004). The Book of Tells. New York: Doubleday.

Cómitre N., I. \& Valverde Z., J.M. (2014). 'How to translate culture-specific items: a case study of tourist promotion campaign by Turespaña'. The Journal of Specialised Translation 21, pp. 71-112. 
Corbacho, J. M., Valderrama, M. \& García, S. (2014). 'The nation brand of Spain on the internet through the "I need Spain" campaign'. Historia y Comunicación Social 19, pp. 501-512.

Crawford, H. J. \& Gregory, G. D. (2015). 'Humorous advertising that travels: A review and call for research'. Journal of Business Research 68 (3), pp. 569-577.

Critchley, S. (2013). On Humour. London: Routledge.

Dore, M. (2018). 'Controversial humor in advertising', in Maon, F., Lindgreen, A., Vanhamme, J., Angell, R. \& Memery, J. (eds.), Not All Claps and Cheers: Humor in Business and Society Relationships. London: Routledge, pp. 132-146.

Eisend, M. (2009). 'A meta-analysis of humor in advertising'. Journal of the Academy of Marketing Science 37 (2), pp. 191-203.

Falconer, E. (2017). 'Learning to be zen: women travellers and the imperative to happy'. Journal of Gender Studies 26 (1), pp. 56-65.

Fernández, A. M. (2017). 'Humor as a teaching resource'. Revista Educación 41 (1), pp. 173 188.

Francesconi, S. (2017). 'Dynamic intersemiosi as a humour-enacting trigger in a tourist video'. Visual Communication 16 (4), pp. 395-425.

Franzini, L. R. (2012). Just Kidding: Using Humor Effectively. Plymouth: Rowman and Littlefield.

Frew, E. A. (2006). 'The humour tourist: A conceptualisation'. Journal of Business Research 59, pp. 643-646.

Fry, W. F. (2011). Sweet Madness: A Study of Humor. Piscataway: Transaction Publishers.

Fuentes-Luque, A. (2016). 'Branding and selling a country through translated tourism advertising: Spain's image'. Revista de Lenguas para Fines Especificos 22 (2), pp. 84-103.

Garín-Muñoz, T. \& de Juan, R. (2012). 'La imagen de España como destino turístico'. Panorama Social 16, pp. 106-124.

Geuens, M., De Pelsmacker, P. \& Faseur, T. (2011). 'Emotional advertising: Revisiting the role of product category'. Journal of Business Research 64 (4), pp. 418-426.

Goldstein, J. H. (ed.). (2013). The Psychology of Humor: Theoretical Perspectives and Empirical Issues. Cambridge, MA: Academic Press.

Haiko, M. (2015). Destination Image and Brand Element Familiarity Among Foreign Tourists. Degree Programme in Tourism. Tampereen ammattikorkeakoulu. Retrieved 3 August 2018 from http://www.theseus.fi/handle/10024/101263

Hampes, W. P. (2010). 'The relation between humor styles and empathy'. Europe's Journal of Psychology 6 (3), pp. 34-45.

Hatzithomas, L., Zotos, Y., \& Boutsouki, C. (2011). 'Humor and cultural values in print advertising: a cross-cultural study'. International Marketing Review 28 (1), pp. 57-80.

Hultén, B. (2011). 'Sensory marketing: the multi-sensory brand-experience concept'. European Business Review 23 (3), pp. 256-273.

Io, M. (2013). 'Testing a model of effective interpretation to boost the heritage tourism experience: a case study in Macao'. Journal of Sustainable Tourism 21 (6), pp. 900-914.

Kemp, E., Childers, C. Y. \& Williams, K. H. (2012). 'Place branding: creating self-brand connections and brand advocacy'. Journal of Product \& Brand Management 21 (7), pp. 508-515.

Kuipers, G. (2015). Good Humor, Bad Taste: A Sociology of the Joke. Berlin and New York: Mouton de Gruyter.

Open-access journal | www.europeanjournalofhumour.org 
Lewis, R.D. (2006). When Cultures Collide: Leading Across Cultures. Boston: Nicholas Brealey International.

Llorens Bahena, F. (2013). 'The promotion of tourism in Spain. From stereotype to brand image', in Manca, E. \& Bianchi F. (eds.), Tourism and Tourist Promotion Around the World: A Linguistic and Socio-cultural Perspective, pp. 5-19.

Lynch, O. H. (2002). 'Humorous communication: Finding a place for humor in communication research'. Communication theory 12 (4), pp. 423-445.

Madden, T. J. \& Weinberger, M. G. (1984). 'Humor in advertising: A practitioner view'. Journal of Advertising Research 24, pp. 23-29.

Mahony, D. L., Burroughs, W. J. \& Lippman, L. G. (2002). 'Perceived attributes of healthpromoting laughter: A cross-generational comparison'. The Journal of Psychology 136 (2), pp. 171-181.

Mariottini, L. (2012). 'I need Spain. Análisis pragmático de la campaña de promoción turística 2010' / 'I need Spain. Pragmatic analysis of the 2010 tourism promotion campaign'. Pasos 10 (4), pp. 105-113.

Marra, M. \& Holmes, J. (2007). 'Humour across cultures: Joking in the multicultural workplace'. Handbook of intercultural communication 7, pp. 153-172.

Martin, R. A. \& Ford, T. (2018). The Psychology of Humor: An Integrative Approach. Cambridge, MA: Academic press.

Martínez, E. \& Nicolás, M. Á. (2013). 'Andalucía as Tourist Destination: Analysis of Advertising Campaigns "Smail You Are In Andalucía" and "Andalucía Loves You". Cuadernos de Turismo 32, pp. 329-331.

Mestre, R., Del Rey, A. \& Stanishevski, K. (2008). 'The image of Spain as tourist destination built through fictional cinema'. Journal of Travel \& Tourism Marketing 24 (2-3), pp. 185 194.

Mirna, C. \& Igor, V. (2016). 'Destination Branding-The Unique Destination Proposition Creation: Mediterranean as it should be'. Journal of Tourism Research \& Hospitality 5 (S2), pp. 1-9.

Mitas, O., Yarnal, C. \& Chick, G. (2012). 'Jokes build community: Mature tourists' positive emotions'. Annals of Tourism Research 39 (4), pp. 1884-1905.

Morgan, N. \& Pritchard, A. (2001). Advertising in Tourism and Leisure. Oxford: ButterworthHeinemann.

Morreall, J. (2014). 'Humor, philosophy and education'. Educational Philosophy and Theory 46 (2), pp. 120-131.

Morris, J. D. \& Boone, M. A. (1998). 'The effects of music on emotional response, brand attitude, and purchase intent in an emotional advertising condition'. Advances in Consumer Research 25, pp. 518-526.

Neuendorf, K. A. \& Skalski, P. (2001). 'Senses of humor: The development of a multi-factor scale in relationship to moving image utility'. Paper presented at the International Communication Association, Acapulco, Mexico.

Nobs F., M. L. (2006). La traducción de folletos turísticos. ¿Qué calidad demandan los turistas? [The Translation of Tourist Brochures. Which Quality Are Tourists Demanding?] Granada: Comares.

Noya, J. (2003). 'Luces y sombras de la acción cultural exterior'. Boletín Elcano 22, pp. 1-7.

Pabel, A \& Pearce, P. L. (2015). 'Highlighting the benefits of tourism humour: The views of tourists'. Tourism Management Perspectives 16, pp. 357-364. 
Pabel, A. \& Pearce, P. L. (2016). 'Tourists' responses to humour'. Annals of Tourism Research 57, pp. 190-205.

Pabel, A. \& Pearce, P. L. (2018). 'Selecting humour in tourism settings-A guide for tourism operators'. Tourism Management Perspectives 25, pp. 64-70.

Pabel, A. (2017). 'The role of humour in contributing to tourism experiences', in Filep, S., Laing, J. \& Csikszentmihalyi, M. (eds.), Positive Tourism, New York: Routledge, pp. $100-118$.

Panda, T. K., Panda, T. K. \& Mishra, K. (2013). 'Does emotional appeal work in advertising? The rationality behind using emotional appeal to create favourable brand attitude'. IUP Journal of Brand Management 10 (2), pp. 7-23.

Parente, D. \& Strausbaugh-Hutchinson, K. (2014). Advertising Campaign Strategy: A Guide to Marketing Communication Plans. Boston: Cengage Learning.

Pearce, P. L. \& Pabel, A. (2015). Tourism and Humour. Bristol: Channel View Publications.

Peterson, C. \& Seligman, M. E. P. (2004). Character Strengths and Virtues: A Handbook and Classification. Washington, DC: American Psychological Association.

Plumed, M. (2012). 'Evolution of the image of Spain as tourist destination'. European Journal of Tourism Hospitality and Recreation 3, pp. 215-233.

Poria, Y., Reichel, A. \& Biran, A. (2006). 'Heritage site perceptions and motivations to visit'. Journal of Travel Research 44, pp. 318-326.

Refaie, E. E. (2011). 'The pragmatics of humour reception: Young people's responses to a newspaper cartoon'. International Journal of Humor Research 24 (1), pp. 87-108.

Reisinger, Y. \& Steiner, C. (2006). 'Reconceptualising interpretation: The role of tour guides in authentic tourism'. Current Issues in Tourism 9 (6), pp. 481-498.

Reisinger, Y. \& Turner, L. (2012). Cross-cultural Behaviour in Tourism. London: Routledge.

Riecken, G. \& Hensel, K. (2012). 'Using Humor in Advertising: When Does it Work?'. Southern Business Review 37 (2), pp. 27-37.

Rocamora A., R. (2004). 'Cognitive trends in virtual marketing'. Mind Language and Metaphor. EuroConference on the Processing of Metaphor and Metonomy From Computers to Neurospychology. Granada.

Ruch, W. (1998). The Sense of Humor: Explorations of a Personality Characteristic. Berlin and New York: Mouton de Gruyter.

Ruch, W. (2002). 'Humor', in Peterson, C. and Seligman M. E. P. (eds.), The Values in Action (VIA) Classification of Strengths. Cincinnati, $\mathrm{OH}$ : Values in Action Institute.

Saucet, M. \& Cova, B. (2015). 'The secret lives of unconventional campaigns: Street marketing on the fringe'. Journal of Marketing Communications 21 (1), pp. 65-77.

Skalski, P., Tamborini, R., Glazer, E. \& Smith, S. (2009). 'Effects of humor on presence and recall of persuasive messages'. Communication Quarterly 57 (2), pp. 136-153.

Sliter, M., Kale, A. \& Yuan, Z. (2014). 'Is humor the best medicine? The buffering effect of coping humor on traumatic stressors in firefighters'. Journal of Organizational Behavior 35 (2), pp. 257-272.

Smith, M., MacLeod, N. \& Robertson, M. H. (2010). Key Concepts in Tourist Studies. London: Sage.

Spielmann, N. \& Delvert, M. (2014). 'Adapted or standardized copy: Is non-cultural English the answer?'. Journal of Business Research 67 (4), pp. 434-440. 
Storm, H. J. (2013). 'Una España más española. La influencia del turismo en la imagen nacional. Ser españoles'. Imaginarios nacionalistas en el siglo XX. Barcelona: RBA, pp. 530-560.

Strick, M., Holland, R. W., van Baaren, R. B. \& Van Knippenberg, A. (2012). 'Those who laugh are defenseless: How humor breaks resistance to influence'. Journal of Experimental Psychology: Applied 18 (2), pp. 213-249.

Ulloth, J. K. (2002). 'The benefits of humor in nursing education'. The Journal of Nursing Education 41 (11), pp. 476-481.

Valiente, S. (2016). Marcas sonrientes: humor y engagement en publicidad [Smiling Brands: Humour and Engagement in Promotion]. Barcelona: Editorial UOC.

Vuorela, T. (2005). 'Laughing matters: A case study of humor in multicultural business negotiations'. Negotiation Journal 21 (1), pp. 105-129.

Weinberger, M. G. \& Gulas, C. S. (1992). 'The impact of humor in advertising: A review'. Journal of Advertising 21 (4), pp. 35-59.

Weinberger, M. G., Gulas, C. S. \& Weinberger, M. F. (2015). 'Looking in through outdoor: a socio-cultural and historical perspective on the evolution of advertising humour'. International Journal of Advertising 34 (3), pp. 447-472.

Yeoman, I., Brass, D. \& McMahon-Beattie, U. (2007). 'Current issue in tourism: The authentic tourist'. Tourism Management 28, pp. 1128-1138.

Yus, F. (2016). Humour and Relevance. Amsterdam: John Benjamins. 